Gut, 1986, 27, 954-957

\title{
Partial gastric diverticula: radiological and endoscopic features in six patients
}

\author{
R J DICKINSON AND A H FREEMAN \\ From the Departments of Medicine and Radiology, Hinchingbrooke Hospital, Huntingdon, Cambs
}

SUMmaRY Partial gastric diverticula are rare and clinically insignificant, but because experience is limited, they are liable to cause diagnostic confusion. This report describes the radiological and endoscopic appearances of partial gastric diverticula.

\begin{abstract}
Methods
PATIENTS

Details of the patients are given in the Table. In every instance barium meal was carried out as part of the investigation of a history of dyspepsia. Because of the radiological findings, four of the patients had subsequent gastroscopy.

RADIOLOGICAL FINDINGS

The hallmark of this lesion is its site, being found invariably on the greater curve of the stomach within a few centimetres of the pylorus. Radiologically, the lesion may show a central 'pit' of barium no more than 1-2 $\mathrm{mm}$ deep (Fig. 1). As such, it would appear to be contained entirely within the

Address for correspondence: Dr A H Freeman. Department of Radiology, Addenbrooke's Hospital, Hills Road. Cambridge CB2 $20 Q$.

Received for publication 13 December 1985.
\end{abstract}

gastric wall, a point emphasised by Treichel et al. ${ }^{1}$ The collection of barium is either linear or oval in appearance and has a well defined edge. Another characteristic is that the central depression is surrounded by a submucosal mound usually no more than $2 \mathrm{~cm}$ in diameter (Fig. 2). This particular appearance can easily be simulated by a submucosal tumour such as a leiomyoma, but it would be most unusual for such small leiomyomas to ulcerate at this early stage. The alternative diagnosis, that of a benign peptic ulcer surrounded by oedema has been excluded by endoscopy and/or follow up in our cases.

In one case the lesion had a somewhat different appearance in that although the single contrast films show a lesion in the classic site, it appears to consist of two separate pits with a larger one lying distally (Fig. 3). After air insufflation and Buscopan, however, these two merged into one single lesion which then exhibited the characteristics described

Table Details of patients and investigations.

\begin{tabular}{|c|c|c|c|c|c|c|c|}
\hline No & Initial & Age & Sex & Presenting complaints & Barium meal diagnosis & Endoscopic diagnosis & $\begin{array}{l}\text { Final clinical } \\
\text { diagnosis }\end{array}$ \\
\hline 1 & RB & 42 & $\mathbf{M}$ & $\begin{array}{l}\text { Epigastric pain, } \\
\text { Heartburn }\end{array}$ & $\begin{array}{l}\text { Hiatus hernia } \\
\text { Pit in antrum ?nature }\end{array}$ & $\begin{array}{l}\text { ?Pancreatic } \\
\text { heterotopia }\end{array}$ & Oesophageal reflux. \\
\hline 2 & HA & 45 & $\mathbf{M}$ & Epigastric pain & $\begin{array}{l}\text { Pit in antrum, } \\
\text { ?ectopic pancreas }\end{array}$ & ?Ulcerating leiomyoma & Functional dyspepsia \\
\hline 3 & MS & 38 & $\mathbf{F}$ & $\begin{array}{l}\text { Epigastric pain, } \\
\text { Vomiting }\end{array}$ & Gastric ulcer & ?Diverticulum & Functional dyspepsia \\
\hline 4 & EL & 47 & $\mathbf{M}$ & $\begin{array}{l}\text { Epigastric pain, } \\
\text { Nausea }\end{array}$ & Gastric polyp & Diverticulum & Functional dyspepsia \\
\hline 5 & RP & 32 & $\mathbf{M}$ & Epigastric pain & Diverticulum & ND & Functional dyspepsia \\
\hline 6 & LC & 55 & $\mathbf{F}$ & Epigastric pain & Diverticulum* & ND & Functional dyspepsia \\
\hline
\end{tabular}

*This patient had a barium meal 24 years previously which demonstrated the same lesion and was then diagnosed as a prepyloric gastric ulcer. 


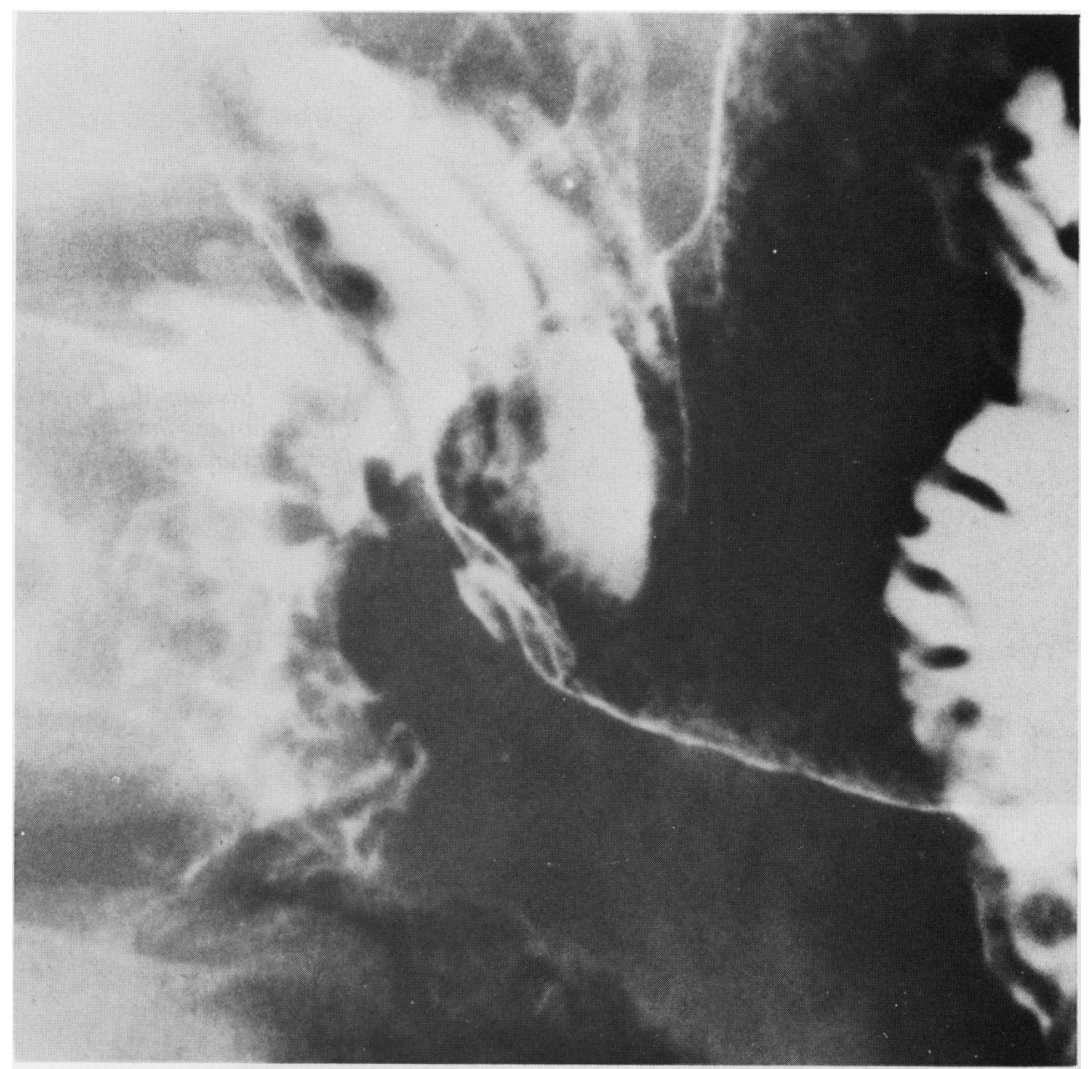

Fig. 1 Supine oblique view of the barium meal on case 5, showing the typical 'pit' of barium on the greater curve of the stomach in the immediate prepyloric region. Note the surrounding soft tissue mound.

above. The value of hypotonia and air insufflation is also stressed by Treichel et al. ${ }^{1}$

\section{ENDOSCOPIC FINDINGS}

Gastroscopy was carried out in four patients. In each instance the presence of an abnormality was confirmed on the greater curve, proximal to the pylorus. The lesions were approximately $1 \mathrm{~cm}$ in diameter. In three instances the lesion appeared raised with a central dimple whilst in the remaining one it was depressed (Fig. 4a and b). In two patients the correct diagnosis was made while in the others ulcerating leiomyoma and pancreatic heterotopia were proposed respectively.

\section{CLINICAL OUTCOME}

One patient was treated for two months with ranitidine and another was treated with antacids for a provisional diagnosis of gastric ulcer whilst awaiting gastroscopy. Case 6 was of interest in that she presented with a probable haematemesis in 1960 and a diagnosis of gastric ulcer made, but this episode settled spontaneously. The barium meal appearances 24 years later were exactly the same, suggesting that the original diagnosis was probably incorrect and that the lesion was an intramural diverticulum.

\section{Discussion}

The term partial gastric diverticulum was coined by Samuel $^{2}$ and defined as a projection of the gastric mucosa into the muscle layer which does not extend to the serosa. This is very rare and there were only 14 cases in the world literature after the report of Flachs et al in $1965 .{ }^{3}$ Since then there have been other reports by Rabushka et al, ${ }^{4}$ Treichel et al, ${ }^{1}$ and Cockrell et $a l^{5}$ and all have confirmed the typical radiology described here. Treichel et al ${ }^{1}$ described four patients discovered during the course 


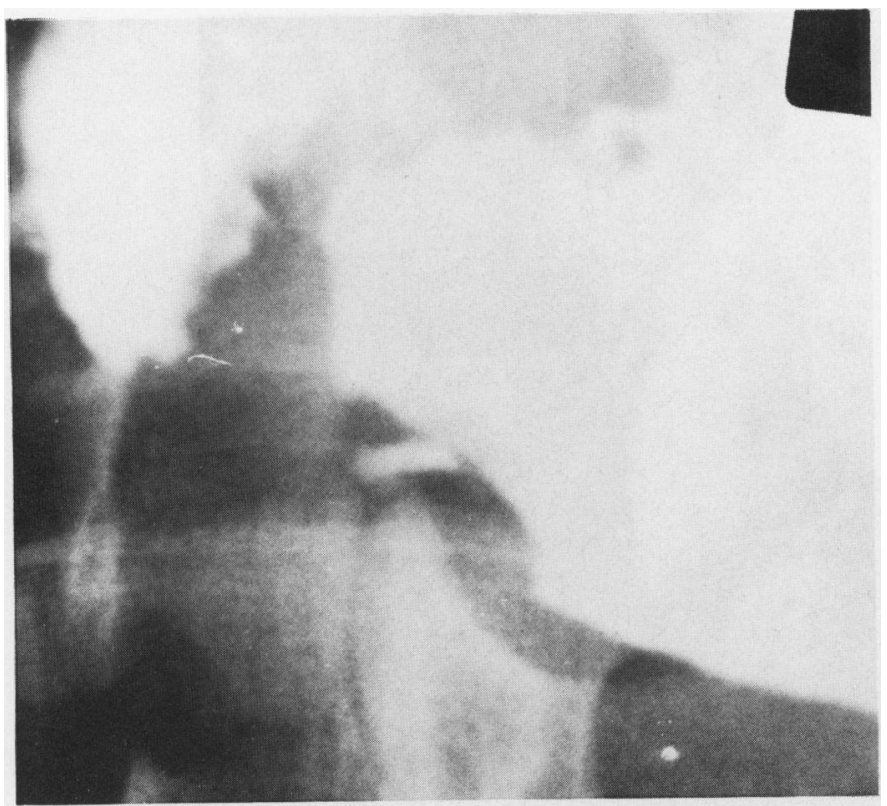

Fig. 2 Barium filled view of the same case as Fig. 1 showing the submucosal mound to better advantage.

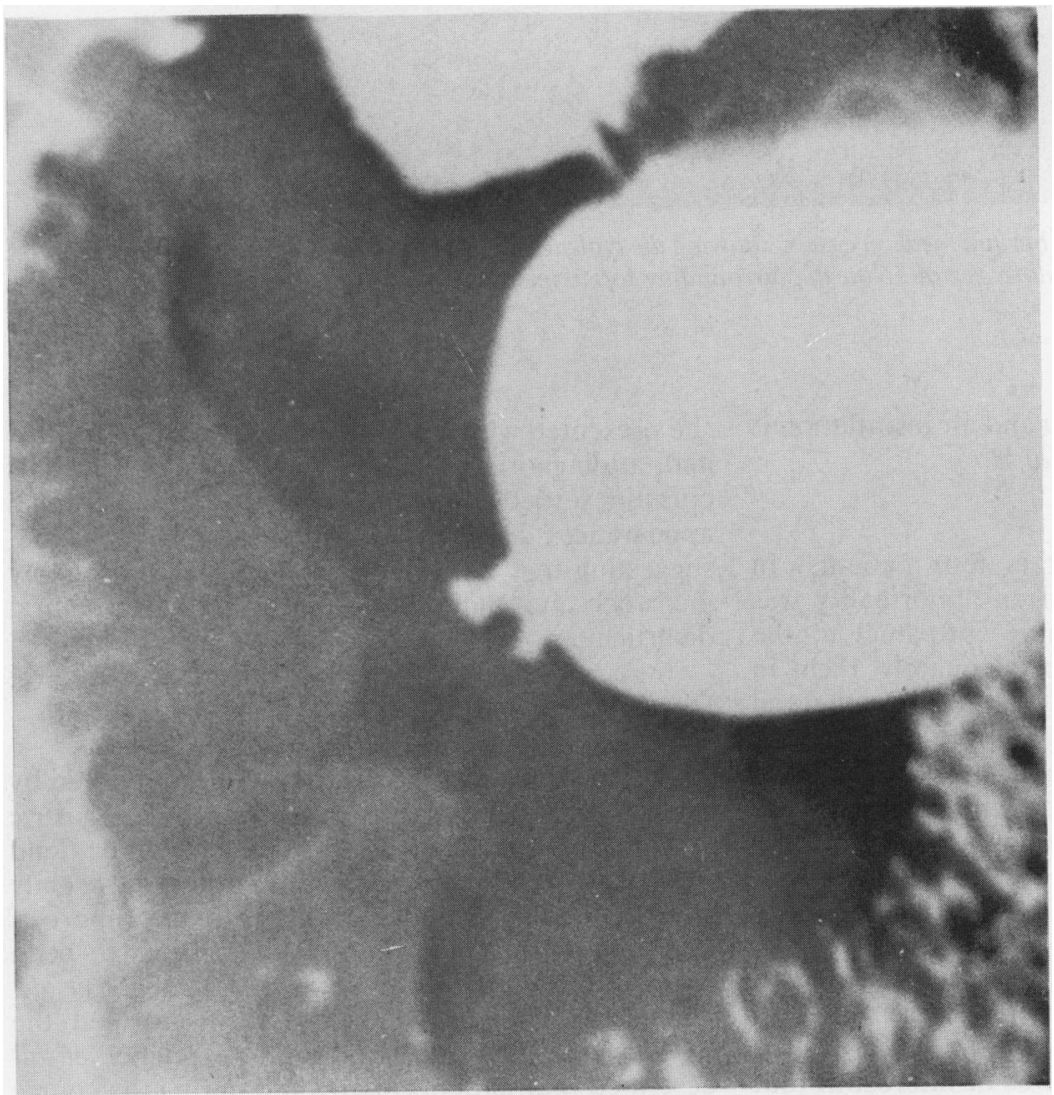

Fig. 3 Barium filled view of the stomach from case 1 showing two adjacent 'pits' of barium on the greater curve of the stomach. These merged into one with hypotonia and air insufflation. 

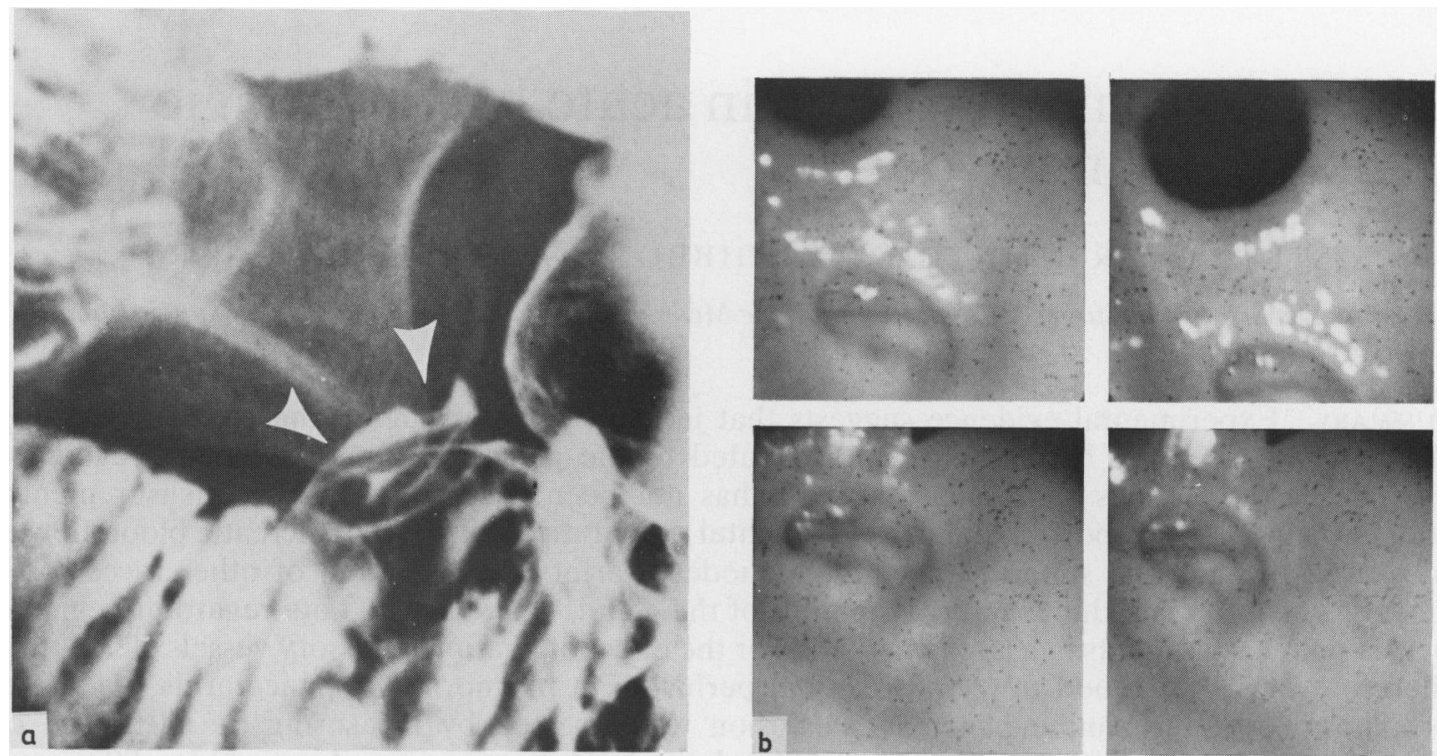

Fig. 4 (a) Air contrast view of the prepyloric area of case 3 showing the typical niche of barium (arrow heads) surrounded by a mucosal 'collar'. (b) Four endoscopic views of case 3 showing the orifice of the diverticulum just proximal to the pylorus.

of 10000 barium meal examinations - a figure which may give a fair indication of the frequency of the abnormality in the dyspeptic patient.

The typical radiological and endoscopic appearances described here should lead to greater recognition of this lesion in the future. This is to be encouraged in order to prevent the mistaken diagnosis of gastric ulcer which has led on one occasion at least to partial gastrectomy. ${ }^{3}$

We thank our colleagues for allowing us to report patients under their care.

\section{References}

1 Treichel J, Gerstenberg E, Palme G, Klemm T. Diagnosis of partial gastric diverticula. Radiology 1976; 119: $13-8$.

2 Samuel E. Gastric diverticula. Br J Radiol 1955; 28: 574-8.

3 Flach K, Stelman HH, Matsumoto PJ. Partial gastric diverticula. Am J Roentgenol 1965; 94: 339-42.

4 Rabushka SE, Melamed M, Melamed JJ. Unusual gastric diverticula: report of two cases. Radiology 1968; 90: 1006-8.

5 Cockrell CH, Cho SR, Messmer JM, Shaw CI, Liu CI. Intramural gastric diverticula: a report of three cases. Br J Radiol 1984; 57: 285-8. 